\title{
FACULTY AT WORK: Focus on Research, Scholarship, and Service
}

\author{
Robert T. Blackburn, Jeffery P. Bieber, \\ Janet $H$. Lawrence, and Lois Trautvetter
}

\begin{abstract}
Within the framework of cognitive motivation theory, selected personal and environmental motivational variables for faculty in eight liberal arts and science departments from community colleges, liberal arts colleges, comprehensive colleges and universities, and research universities were regressed against faculty allocation of work effort given to research, scholarship, and service. The data came from a 1988 national survey of faculty. Gender, (sociodemographic), quality of graduate school attended, career age, and rank (career); self-competence and self-efficacy regarding research, scholarship, and service and percent time prefer to give to research, scholarship, and service (self-valuations); and institutional preference, consensus and support, and colleague commitment to research, scholarship, and service (perception of the environment) were entered into regressions. $R^{2} s$ were generally strong (.64 for liberal arts-I institutions) and significani. For all institutional types, selfvaluation (self-competence and -efficacy) motivators significantly accounted for the explained variance. Sociodemographic and career variables did not explain appreciable amounts of variance.
\end{abstract}

Knowledge production once was almost exclusively conducted in research and doctoral-granting universities. Today, however, faculty in almost every institutional type perceive pressure to obtain external funding, conduct research, and publish their findings. Even in liberal arts colleges, with their strong teaching mission, junior faculty find that good teaching evaluations are no longer sufficient to obtain tenure.

The increasing emphasis on the faculty research role may be the result of administrators' desires for enhanced institutional reputation and economic stability or an increased interest on the part of the faculty to conduct research as a consequence of their graduate school training. Regardless of the reason, faculty

Address correspondence to: Dr. Robert T. Blackburn, Center for the Study of Higher and Postsecondary Education, 2117 School of Education, The University of Michigan, Ann Arbor, MI 48109-1259. 
at all institutional types indicate that they prefer to give more of their work effort to research than they currently are. They would secure the needed extra time by reducing the effort they now give to service. They prefer the effort they give to teaching to stay about as it is (Carnegie Foundation, 1989).

As a result of these current preferences, empirical studies that have as their focus the research, scholarship, and service roles are important. We need to know the relative effectiveness of different kinds of motivators vis-à-vis faculty behavior and their propensity to engage in these roles.

In an effort to fill this research void, this inquiry had the following objectives: (1) ascertaining the degree to which faculty are engaged in research, scholarship, and service activities; and (2) assessing the relative strength of different kinds of motivators, namely, those that are (a) a consequence of demographic characteristics (gender and age) and career achieved experience (graduate school rating, current rank), (b) self-valuations (competence, efficacy, commitment, interest, role preference), and (c) perceptions of the environment (institutional and collegial support, colleague commitment to the roles, beliefs about what the institution prefers).

\section{LITERATURE AND THEORETICAL FRAMEWORK}

Before addressing the literature and theoretical components of this study, important definitions are clarified. Distinctions are made between the concepts of research and scholarship. Research is defined as an activity that results in a product-an article, for example. Scholarship, on the other hand, is defined on the survey from which the data for this study come as professional growthtime spent enhancing knowledge or skill in ways that may not necessarily result in a concrete product-library work, reading, exploratory inquiries, computer use.

An extensive literature exists on the correlates of faculty research. Finkelstein (1984) presents a systematic review of a large set of studies, although his book is becoming dated in light of the increasing research output on faculty. Creswell (1985) provides a good, partial update.

As of late, correlational studies have come to the fore. There is, however, a principal weakness in many of them, namely, the limited type of predictor variables that are employed. Astin (1984) is one who has noted this shortcoming. She states that "Researchers have usually looked at the following factors as potential predictors or independent variables: (1) gender, (2) marital status, (3) age, (4) field of specialization, (5) educational experience and characteristic of the graduate institution, (6) charactristics of the employer institution" (p. 263).

While correlations have been found between faculty behaviors (most often research) and these respective predictors, seldom are there strong relationships. 
In fact, there are instances of contradictory outcomes. For example, chronological age has been both a positive and a negative predictor of faculty scholarly output (Bentley and Blackburn, 1990).

In addition to weak and contradictory outcomes, the research using these variables is often atheoretical. Why the above variables have been selected is not made clear nor is it apparent that they serve as indicators of constructs within some conceptual scheme. It is possible, however, to attach motivational links to most of them.

For example, gender and age are demographic variables, that is, ascribed characteristics that can be thought of as surrogates within need motivation theory. Need theory would say that women's supportive and cooperative nature motivates them to favor teaching over research. Gender, of course, contains richer and more complex dimensions than a need to nurture. For example, from Gilligan (1982) and others we know a feminist perspective provides fresh insights on many intellectual issues. Consequently, we retain the gender variable for multiple reasons. ${ }^{1}$

In life-stage theory, age is an important variable. It purports that people have different needs at successive points in time, and these needs motivate behavior. As male faculty age, their need for affiliation increases. Similarly, their interest in teaching increases as they approach retirement (Baldwin and Blackburn, 1981).

The next three variables that Astin refers to (numbers 4, 5, and 6) are important with respect to socialization theory. This theory would predict that earning a $\mathrm{Ph} . \mathrm{D}$. both trains one on how to conduct research and transmits the value accorded to teaching. That is, socialization theory predicts that Ph.D. recipients of Research-I institutions (Carnegie, 1987) will be less interested in teaching than those who graduated from universities in all other Carnegie classifications. Said another way, faculty have been socialized to value certain activities early in their careers and the attractiveness of these activities persists over their careers. Given the high degree of autonomy that faculty enjoy, it follows that faculty will engage in those activities that they find most attractive (Finkelstein, 1984).

A third set of motivators (but not discussed by Astin) has to do with organizational and institutional rewards and incentives. Tuckman and Leahey (1975), for example, found high correlations between salary and numbers of articles published. Ladd and Lipset (1975) found that a faculty member's first concern in moving to a different institution is salary. On the other hand, Finkelstein's (1984) review of literature led him to conclude that faculty behavior is not related to institutional incentive structures. While reward structures most frequently are identified with the institution in the form of salary, promotions, distinguished titles, and the like, national professional associations also can 
bestow honors and prestige. These honors, however, probably do not represent important incentives for faculty with respect to their behavior.

In contrast to the vast literature on faculty research activity and related issues, there is almost no research on faculty in scholarship and services roles. For scholarship, virtually nothing exists. For service, Boyer and Lewis (1985) have made a genuine contribution by providing an excellent review of faculty consulting. Our survey respondents (see below) reported both internal (institutional committees, senates) and external service (to professional associations, industry). Since the specific activities in which faculty were engaged are not known, and because it is the extent of the behavior rather than what faculty exactly do that matters, total effort allocated to scholarship and effort allocated to service are used as the dependent variables.

What is not known with respect to either faculty research, scholarship, or service activities is how faculty assess their own skills and desires in light of their personal perceptions of how the environment will respond to their behaviors. ${ }^{2}$ Based on earlier success using cognitive motivation theory to explain faculty effort given to teaching (Blackburn, Lawrence, Bieber, and Trautvetter, 1991), variables dealing with faculty self-valuations and perceptions of the environment that specifically address research, scholarship, and service activities have been developed for this study. Succinctly, cognitive motivation theory claims that the manner in which people differentially assess their personal abilities and interests interacts with their perceptions of the organization's priorities (what it supports) and causes them to engage extensively in some activities and less frequently in other activities (Bandura, 1977; Staw, 1984).

The translation of this theory into survey items has taken the form of having each subject do a self-evaluation with respect to commitment to research/scholarship/service; level of research/service competence; impact he or she may exert on, for example, getting their research accepted for publication (efficacy); level of interest in research/scholarship/service; and the percentage of their total effort they would prefer to give to each role. As for perceptions of the environment, faculty have reported the degree of consensus and support they experience, how committed their colleagues are to research/scholarship/service, and what percent of their work effort they believe the administration prefers them to devote to the respective activities. In addition, since the survey has data on the other kinds of motivators (e.g., sociodemographic), the relative amount of variance the different types of motivational predictors possess can be assessed. As this review suggests, a meaningful and logical way to test these predictors is to enter the indicators of the various motivators in the order in which they have been presented in the review, namely, sociodemographic first, then career socialization variables, self-valuations, and last, perceptions of the environment. This order also possesses the advantage of having a chronology to it-from past to present. 


\section{METHOD}

Data from a national survey conducted by the National Center for Research to Improve Postsecondary Teaching and Learning (NCRIPTAL) were analyzed. The survey, Faculty at Work, was administered from November 1987 to January 1988. The sample was drawn in proportion to the distribution of faculty across the nine Carnegie Institutional Classification types (1987). The institutions within these nine categories were further divided according to their publict private status, thus creating a total of eighteen institutional types. The classification schema allowed for a stratified random sample that corresponds to the national distribution of faculty members across institutional types.

The survey was sent to faculty in eight disciplines (history, English, biology, chemistry, mathematics, political science, psychology, and sociology) representing the humanities, natural/physical sciences, and social sciences. The reason for selecting these specific disciplines was that they exist on all campuses. In those instances where a department had 30 or fewer faculty members, questionnaires were sent to everyone in the department. When there were more than 30 faculty in a department, all women and assistant professors were surveyed so as to increase the number of underrepresented groups selected at random until the total from a given department who were in the sample equaled $30 .{ }^{3}$ The survey was completed by 4,400 faculty members ( 54 percent response rate).

The sample respondents well represent the universe of faculty from which they were drawn. When compared with the national faculty surveys conducted in 1969,1975 , and 1980 , our survey requires the smallest correction factors to adjust for actual numbers of faculty in these disciplines and institutional types (Bentley, Blackburn, and Bieber, 1991).

Faculty at Work was designed to gather data on faculty perceptions of their work environment, their own competency and efficacy as faculty members, their assumptions about teaching, and their research, teaching, and service behaviors. The questions about the work environment varied in degree of abstraction. For example, some questions focused on respondents' perception of institutional role expectations and goals of undergraduate education whereas other questions addressed the adequacy of collegial and physical resources (e.g., laboratory, library, computing facilities) and the effectiveness of administrators to whom they report.

The self-competence and self-efficacy items were developed on the basis of extensive interviews conducted with faculty members on diverse campuses. Survey respondents rated themselves on skills associated with valued faculty members on their campuses (competence) and on their ability to bring about desired results (e.g., having their research published) or to bring about changes in their institutions (efficacy). The faculty members were also asked to indicate 
how often they engaged in certain teaching, research, scholarship, and service activities.

\section{ANALYSIS}

In this study, responses from faculty in all Carnegie institutional types were used (except for private two-year institutions). These institutions span the spectrum of faculty role expectations: from very little research and medium-sized classes with no graduate student assistance in community colleges to a significant research effort and graduate seminars mixed with large classes and supervising TAs in research universities.

In all research, scholarship, and service analyses, sociodemographic and career variables were used. With respect to the sociodemographic variables, race was dropped since the $N$ 's in any ethnic group except Caucasian were too small to permit analyses. Age was not used since (1) the research literature has shown it to be a poor predictor for almost all outcome variables used on faculty (Blackburn and Lawrence, 1986) and (2) it is highly co-related to career age (see below), a stronger predictor variable and one that is retained in this set of career variables (Lawrence and Blackburn, 1985). Gender was kept in the analyses (1) as a surrogate for need differences related to sex and (2) because some of the earlier findings of its relationship to scholarly productivity (see, for example, Astin, 1978).

As for career variables, rank, where faculty obtained their highest degree (Research-I versus any other type of institution), and career age (number of years as a faculty member at any type of institution) were used.

Retest reliability coefficients are in parentheses following the items. (See Blackburn and Mackie, 1990, for full details.) Also, other studies have shown faculty accurately report self data such as rank, number of publications, and the like (see Allison and Frank, 1974, Blackburn, Boberg, O'Connell, and Pellino, 1980; Clark and Centra, 1985).

Apart from the variables identified above that were used in all three analyses, the variables discussed below, categorized by their specific analysis, were used.

\section{RESEARCH}

\section{Self-Valuation}

Self-competence: How characteristic obtaining grants is of you $(r=.78)$; how characteristic publishing is of you $(r=.81) .^{4}$

Self-efficacy: How much influence you have on having your writing accepted for publication $(r=.60)$; how much influence you have in obtaining money for travel to professional meetings beyond the standard institutional allowance $(r=.51)$. 
Commitment to research/personality: How characteristic being ambitious $(r=.55)$, competitive $(r=.44)$, persevering $(r=.62)$, and highly committed to research $(r=.73)$ is of you.

Interest: Whether your interests lie heavily in research or in both research and teaching but leaning toward research.

Personal preference: The percentage of time (percent of total time given to faculty activities) you would personally prefer to spend on research-related activities $(r=.83)$.

\section{Perception of the Environment}

Credence: How much credence you give to your chair or dean's comments on your scholarly activities $(r=.53)$; how much credence you give to your colleagues' (faculty members in your unit) comments on your scholarly work $(r=.68)$.

Physical/collegial support: The extent to which it is true that the support services available at your institution for your scholarship help you to conduct the kind of inquiry you desire $(r=.51)$; the extent to which it is true that your unit's colleagues know your specialty well enough to assist and critically review your scholarly work $(r=.49)$.

Financial support: Whether you (or your project) have received research support from any of the following sources in the past twelve months: institution or department; federal agencies; state or local government agencies; private foundations; private industry; other.

Collegial commitment: The extent to which it is true that faculty in your unit and institution are more committed to the teaching of their discipline than they are to adding to their discipline's knowledge base $(r=.70$ and $r=.83$, respectively).

Institutional preference: The percentage of time you believe your institution would prefer that you spend on research activities $(r=.83)$.

In analyzing this research component of the study, three distinct outcome variables were used. The first dependent variable, Level $l$ (clear products), has to do with one's research productivity and is comprised of a seven-item scale how often during the prior two years the subject had

1. submitted an article for publication in an academic or professional journal;

2. published chapters in a book;

3. submitted a research proposal to a governmental or private agency;

4. written a research report for an agency, institutions, or other group;

5. scholarly articles published;

6. external grant proposals submitted; and 
7. professional writings published or accepted for publication.

The second dependent variable, Level 2 (not published products), was comprised of two items: how often the subject had presented her/his ongoing work on campus during the last year $(r=44)$ and how often during the last two years he/she had made a presentation at a professional conference $(r=.81)$.

The third outcome variable, Level 3, collegial conversations regarding research, was a scale comprised of two items having to do with how often the subject had informal conversations with colleagues about research at professional meetings $(r=.71)$ and how often the subject had telephone conversations with colleagues to discuss her/his scholarly work $(r=.77)$.

\section{SCHOLARSHIP}

\section{Self-Valuation}

Self-competency: How characteristic keeping abreast of your discipline is of you $(r=.73)$.

Self-efficacy: How much influence you have vis-à-vis pursuing the personal interests you wish to pursue $(r=.48)$.

Personal preference: The percentage of time you personally prefer to spend on your scholarship $(r=.68)$.

\section{Perception of the Environment}

Physical/collegial support: The extent to which it is true that the support services for teaching at your institution (lab facilities, computers, libraries, clerical assistance, audio-visual aids, student assistance, etc.) help you to teach what and how you would like $(r=.41)$.

Institutional preference: The percentage of time you believe your institution would prefer you to spend on your scholarly activities $(r=.55)$.

The last independent variable was a behavioral variable and consisted of one item: the percentage of time the subject actually devoted to scholarly activities $(r=.65)$.

The dependent variable for the scholarship analysis was a scaled score consisting of three items: how often during the last year you attended a visiting lecturer's presentation on campus $(r=.73)$, had telephone conversations with colleagues to discuss scholarly work $(r=.77$ ), and went off-campus to attend a meeting on the teaching of your discipline $(r=.72)$.

\section{SERVICE}

\section{Self-Valuation}

Self-competence: How characteristic communicating well $(r=.51)$ and responding to requests $(r=.28)$ is of you. 
TABLE 1. Selected Demographic and Career Variables (Percents)

\begin{tabular}{lccccccccc}
\hline & R-I & R-II & D-I & D-II & C-I & C-II & LA-I & LA-II & CC \\
\cline { 2 - 9 }$N$ & $(597)$ & $(244)$ & $(360)$ & $(251)$ & $(996)$ & $(135)$ & $(194)$ & $(263)$ & $(845)$ \\
Female & 18 & 23 & 19 & 19 & 19 & 23 & 30 & 35 & 30 \\
Grad R-I & 78 & 60 & 59 & 56 & 51 & 38 & 52 & 32 & 33 \\
Lecturer & 1 & 0 & 0 & 0 & - & 0 & 0 & 1 & 1 \\
Instructor & 0 & 0 & 0 & 0 & - & 1 & 0 & 3 & 18 \\
Assistant Professor & 15 & 30 & 16 & 26 & 18 & 26 & 29 & 24 & 10 \\
Associate Professor & 25 & 35 & 31 & 32 & 31 & 26 & 29 & 31 & 26 \\
Professor & 58 & 35 & 52 & 42 & 50 & 47 & 42 & 41 & 43 \\
Career Age (Actual) & 19 & 17 & 18 & 17 & 18 & 19 & 17 & 16 & 18 \\
\hline
\end{tabular}

Self-efficacy: How much influence you have vis-à-vis departmental curriculum committee decisions $(r=.61)$.

Commitment to service/supportive personality: How characteristic being a team player $(r=.73)$ and being devoted to the institution $(r=.58)$ is of you.

Interest: How characteristic being suportive is of you $(r=.56)$.

Personal preference: Percentage of time you personally prefer to spend on service activities $(r=.47)$.

\section{Perception of the Environment}

Credence: How much credence you give to your chair or dean's comments on your service activities $(r=.50)$.

Consensus and support: The extent to which it is true that you are encouraged by your institution to work for the collective well-being of your unit $(r=.26)$.

Institutional preference: The percentage of time you believe your institution would prefer that you spend on service activities $(r=.61)$.

Like the research dependent variables, the service analysis also contained three dependent variables. The first (public service) was a single item asking the subject how often during the last year he/she had served as a guest on a local radio or television station. ${ }^{6}$

The second dependent variable (professional service) was a factor consisting of four items: How often in the last two years the subject had (1) reviewed articles for a professional journal $(r=.81)$; (2) organized a professional meeting $(r=.61)$; (3) edited the proceedings of a professional meeting $(r=.20)$; and (4) served on an editorial board of a professional journal $(r=.70)$.

The third dependent service variable (institutional service) was a factor consisting of four items: How often during the past five years the subject had (1) participated in campuswide committees dealing with major issues $(r=.79)$; (2) chaired a campus or unit committee $(r=.68)$; (3) played a role in the 
unit's curriculum revision $(r=.58)$; and (4) conducted a study to help solve a unit problem $(r=.56)$.

\section{DESCRIPTIVE RESULTS}

Tables 1 and 2 display the sociodemographic, career, self-valuation, perceptions of the environment, and behavior variables by institutional type that were used in the study. The $N$ 's for each category are shown at the top.

The demographic and career variables show what other studies have demonstrated, namely, that women are underrepresented and more so in universities than in liberal arts and community colleges. That Ph.D.-producing universities (especially R-I universities) have more faculty who graduated from R-I universities has also been established (Breneman and Youn, 1988). Career age is similar across institutional types. The percentage of full professors in R-Is and R-IIs is markedly higher, an indication that research is what matters most in these universities. Visible products will be rewarded by more rapid promotion to those who are successful in this role.

Table 2 displays some of the self-valuation, perception of the environment, and behavior variables. With respect to interest in research, the very high

TABLE 2. Selected Self-Valuations, Perceptions of the Environment, and Behaviors (Percents)

\begin{tabular}{|c|c|c|c|c|c|c|c|c|c|}
\hline & R-I & R-II & D-I & D-II & C-I & C-II & LA-I & LA-II & $\mathrm{CC}$ \\
\hline Interest in Research & 79 & 68 & 51 & 49 & 25 & 13 & 26 & 14 & 7 \\
\hline $\begin{array}{l}\text { Personal Preference } \\
\text { for Research }\end{array}$ & 42 & 36 & 34 & 31 & 19 & 8 & 14 & 9 & \\
\hline $\begin{array}{l}\text { Institution } \\
\text { Preference for } \\
\text { Research }\end{array}$ & 39 & 36 & 32 & 31 & 20 & 15 & 20 & 15 & 10 \\
\hline $\begin{array}{l}\text { Personal Preference } \\
\text { for Scholarship }\end{array}$ & 13 & 11 & 13 & 12 & 12 & 12 & 12 & 11 & 11 \\
\hline $\begin{array}{l}\text { Institution } \\
\text { Preference for } \\
\text { Scholarship }\end{array}$ & 20 & 17 & 18 & 17 & 18 & 17 & 17 & 17 & 17 \\
\hline $\begin{array}{l}\text { Effort Given to } \\
\text { Scholarship }\end{array}$ & 15 & 11 & 13 & 12 & 13 & 11 & 10 & 12 & 11 \\
\hline $\begin{array}{l}\text { Personal Preference } \\
\text { for Service }\end{array}$ & 14 & 16 & 13 & 13 & 15 & 16 & 15 & 15 & 10 \\
\hline $\begin{array}{l}\text { Institution } \\
\text { Preference for } \\
\text { Service }\end{array}$ & 10 & 12 & 11 & 10 & 11 & 11 & 10 & 11 & 11 \\
\hline
\end{tabular}


percentages in research universities and the low percentages in C-II, LA-II, and $\mathrm{CCs}$ are as expected. Personal preferences for time given to research follow the same pattern. Perceived institutional preference for percentage of work effort given to research and personal preference are in agreement in the universities. However, in the two- and four-year colleges, personal preference is less than what faculty believe the administration wants them to allocate to research.

As for scholarship, personal preference and actual effort (in percent time) are in accord and both are less than what faculty perceive their institutions prefer. This is true across all institutional types. Similarly, personal preference and perceived institutional preference for time given to service are essentially the same across all institutional types and, unexpectedly, with faculty preferring to give a little more than they believe the administration wants.

\section{REGRESSION RESULTS}

Fifty-four ${ }^{7}$ regressions were run (six outcome variables for nine institutional types). The results are shown in Tables 3 through 8 . The tables are to be read as described below.

There are two columns within each institutional type column in Table 3 . The first is the $R^{2}$ (percent of variance accounted for) for the outcome variable (Level-1 research, namely, a scale from seven items reporting publishing activities) attributable to all of the variables entered into the regression up to that particular point; the second column number is the significance of the $F$ score for that step in the regression. The entered variables that could contribute significantly to the $R^{2}$ are indicated, along with the significance level for each variable that did contribute significantly.

By way of illustration, note the first two entries for R-I institutions. When the saciodemographic and career variables were entered (step 1 ), $R^{2}=.14$ and $p<.00$. Having earned the highest degree from the non-R-I university and being younger than average in the academic career were each significant at $p<.05 .^{8}$. These two sociodemographic and career variables were entered simultaneously since our conceptual framework does not draw specific causal connections between them. This group was entered first because these surrogate motivation variables have been hypothesized (and tested) to be direct predictors of research behaviors and products.

Self-valuation variables were entered in steps 2 through 5 . (All prior variables are always retained, i.e., controlled for.) Self-competence (step 2) in doing research increased the $R^{2}$ to $.43(p<.00)$, a statistically significant increase. Graduate school and career age remain significant predictors of the outcome variable.

Adding self-efficacy in step 3 significantly increases the $R^{2}$ by .01 to .44 and is itself significant at $p<.01$. The variables present at step 2 remain as predic- 

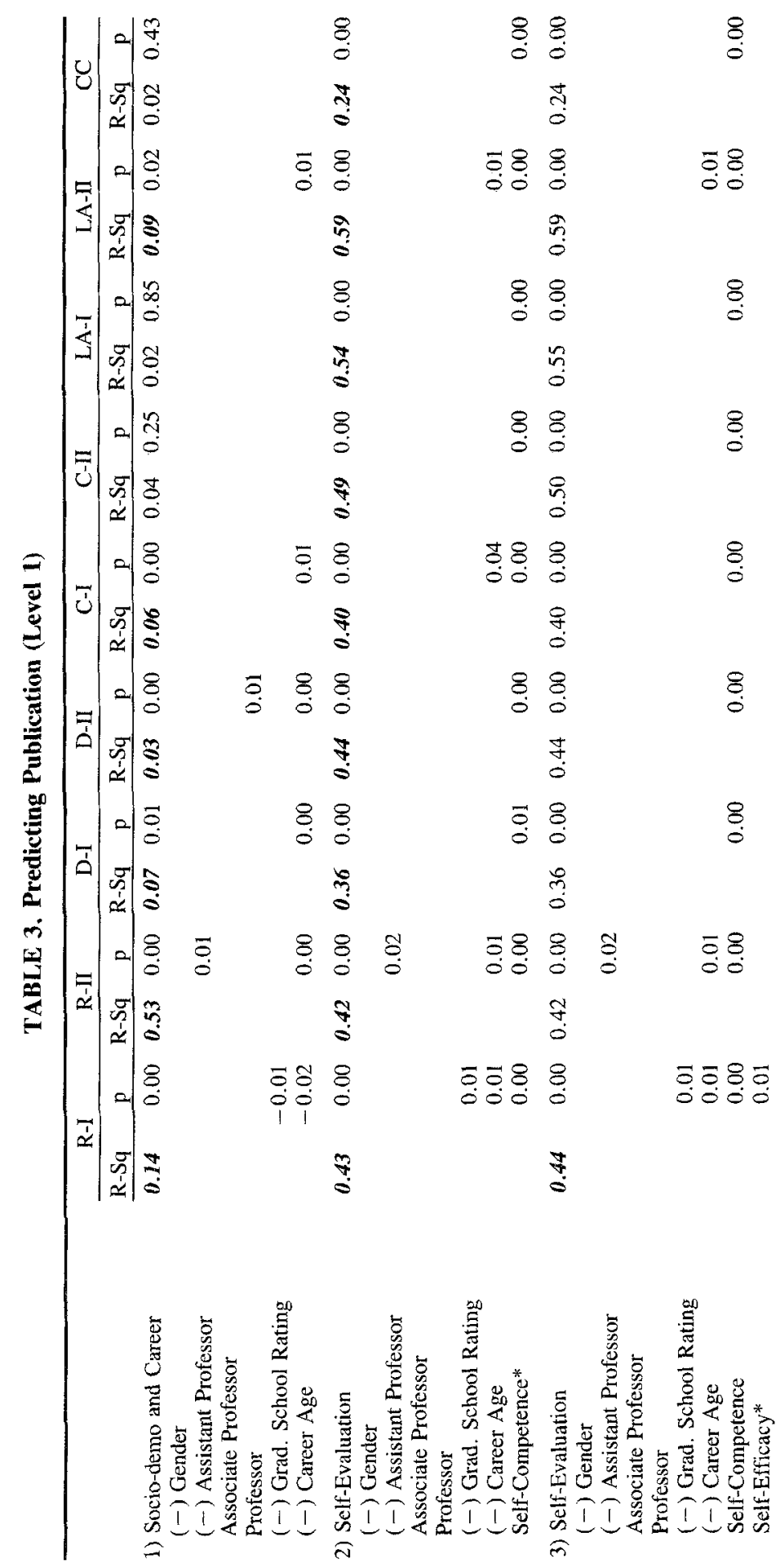

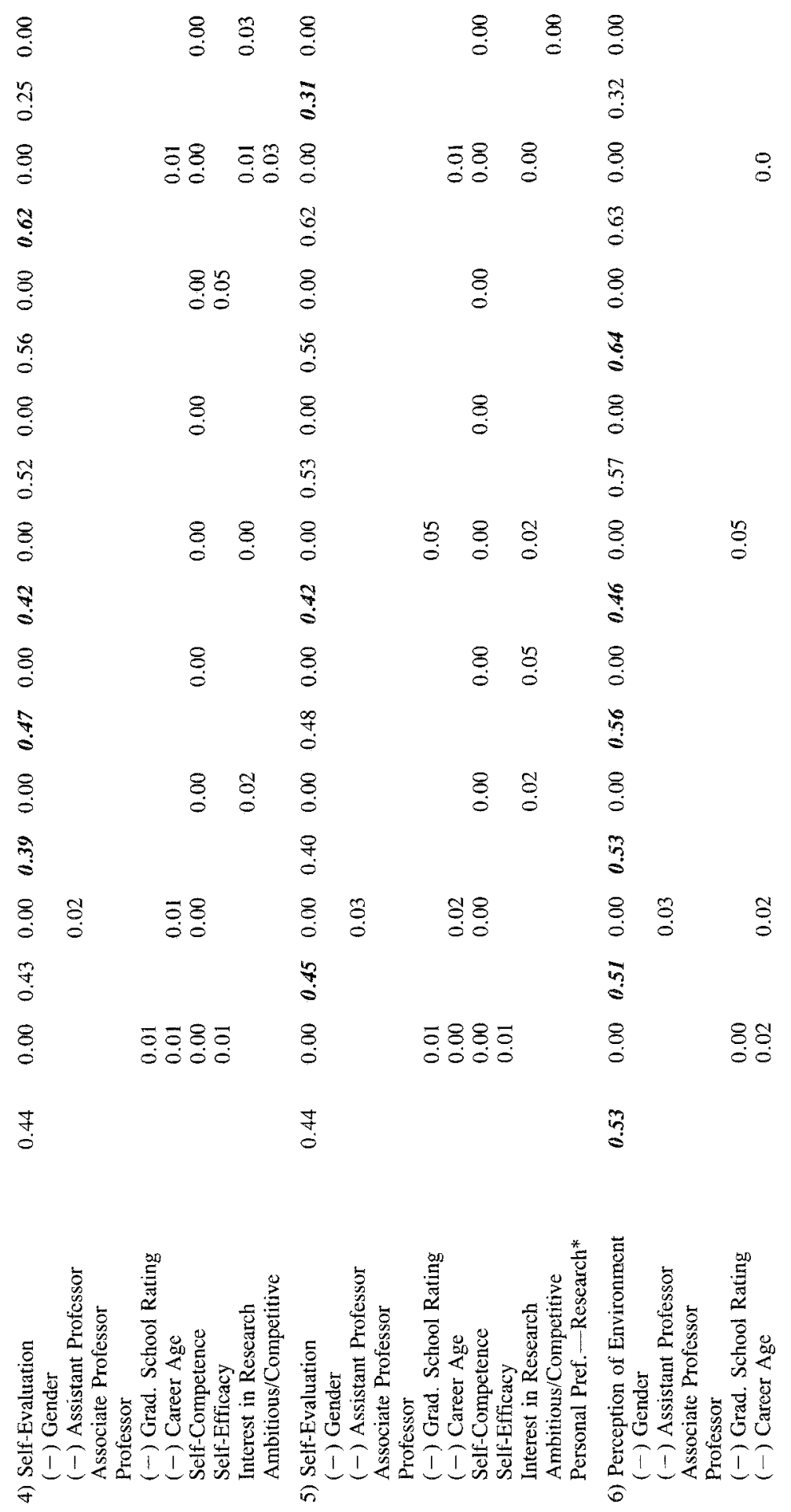


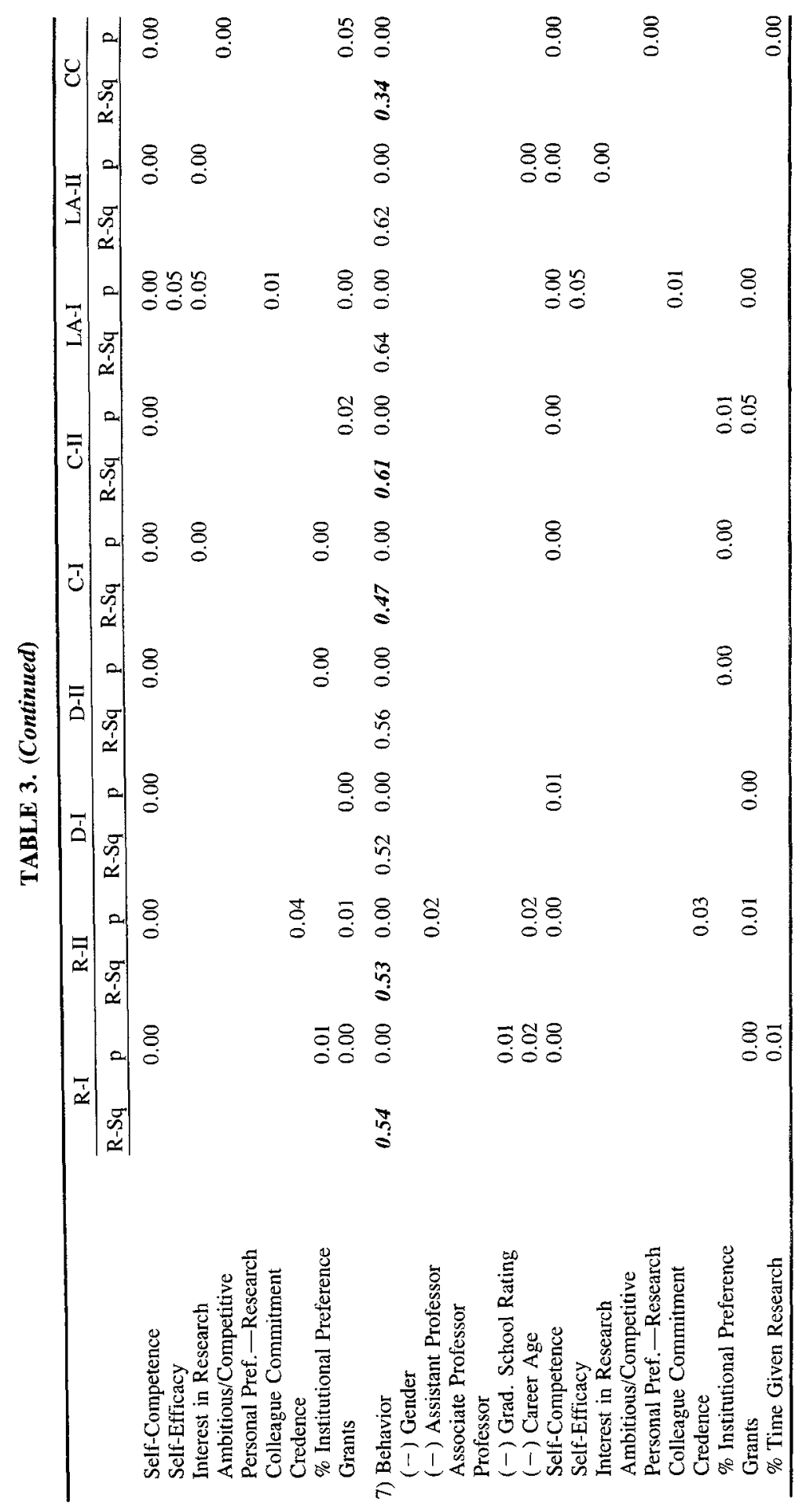


tors. When interest in research and the personal attributes of ambition and competitiveness are entered in step 4, they are not significant. Nothing changes and the $R^{2}$ remains .44 . Step 5 entered how much effort the faculty member personally preferred to give to research. It also produced no change.

Step 6 added five perceptions of the environment variables: preferred percent of effort given to research; colleague commitment to research; credence given to chair and colleague's comments on your research; percent effort you believe the institution wants you to give to research (inst. pref); and the number of grants you had. One of these, the number of different kinds of grants obtained during the past year (financial support), is significant at $p<.00$ while another variable, institutional preference, is significant at $p<.01$. Self-efficacy drops out and is no longer a predictor. Last, in step 7 the faculty behavior of percent of effort given to research significantly increases the $R^{2}$ to .54 and is itself significant at $p<.01$.

R-II through $\mathrm{CC}$ columns are read in the same manner, as are the other five regression tables.

\section{DISCUSSION}

Self-competence and financial support through obtaining grants are the strong predictors of publishing (Level-1 research outcome). The former is significant in all institutional types and the latter in all but LA-IIs and CCs (see Table 2).

Of the sociodemographic and career variables, only career age (in four cases) and rating of institution granting the highest degree (two times) appear. What is new here is that it is the younger who are publishing more (betas are negative when significant), an outcome different from all prior national surveys of faculty. It is also of interest that it is the graduates of non-research-I universities who are the higher publishers. What this finding suggests is that if you have not graduated from an R-I and you are a voracious publisher, you can still be hired at a R-I institution.

It is also worth noting that gender is not a predictor. Unlike most earlier studies that found men published more than women, when self-competence was introduced, gender dropped from the regression. Also, contrary to earlier expectations, interest in research did not predict actual output. This self-valuation variable was used in an earlier study (Blackburn et al., 1991) on teaching and proved to be a strong predictor of effort given to teaching.

As for the second outcome variable of research, making presentations on campus and at conferences (Level-2)--activities that require preparation of research, but not necessarily publications-the $R^{2} s$ are still appreciable. They are not, however, as high as they were for outcome Level 1 (average is .31 vs. .57). Also, the predictors are much the same. Self-competence is significant in seven college and university types and financial support (number of different 


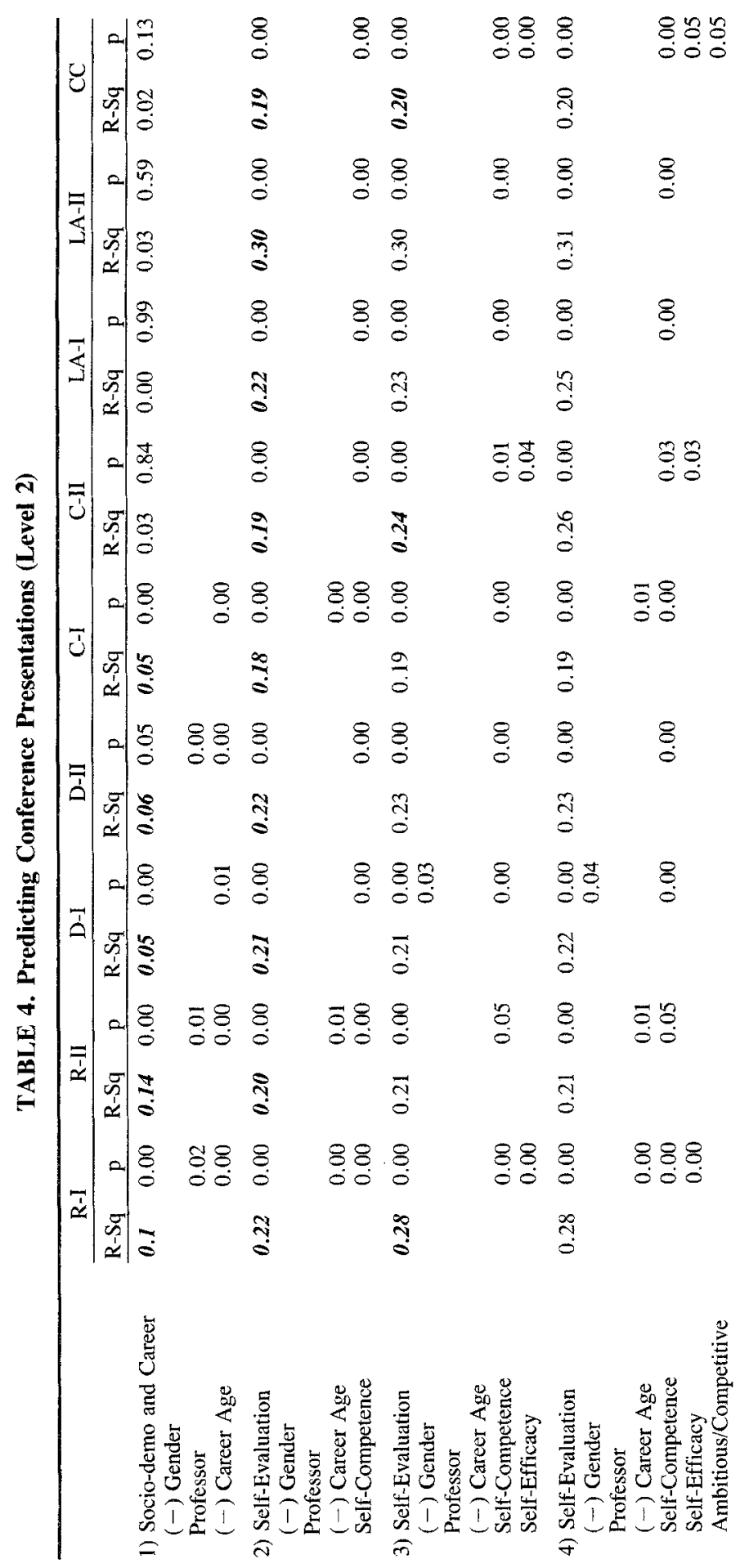




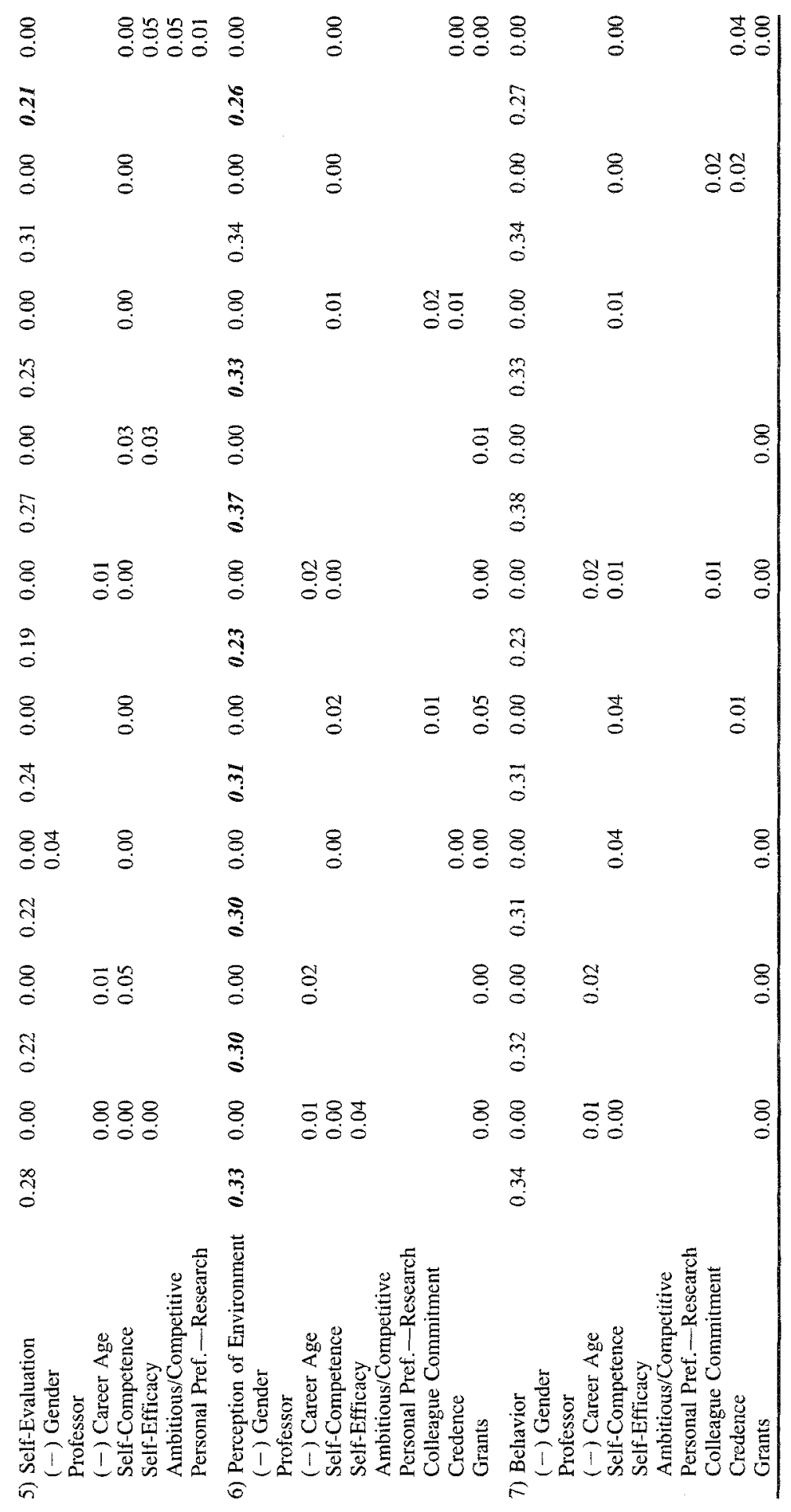




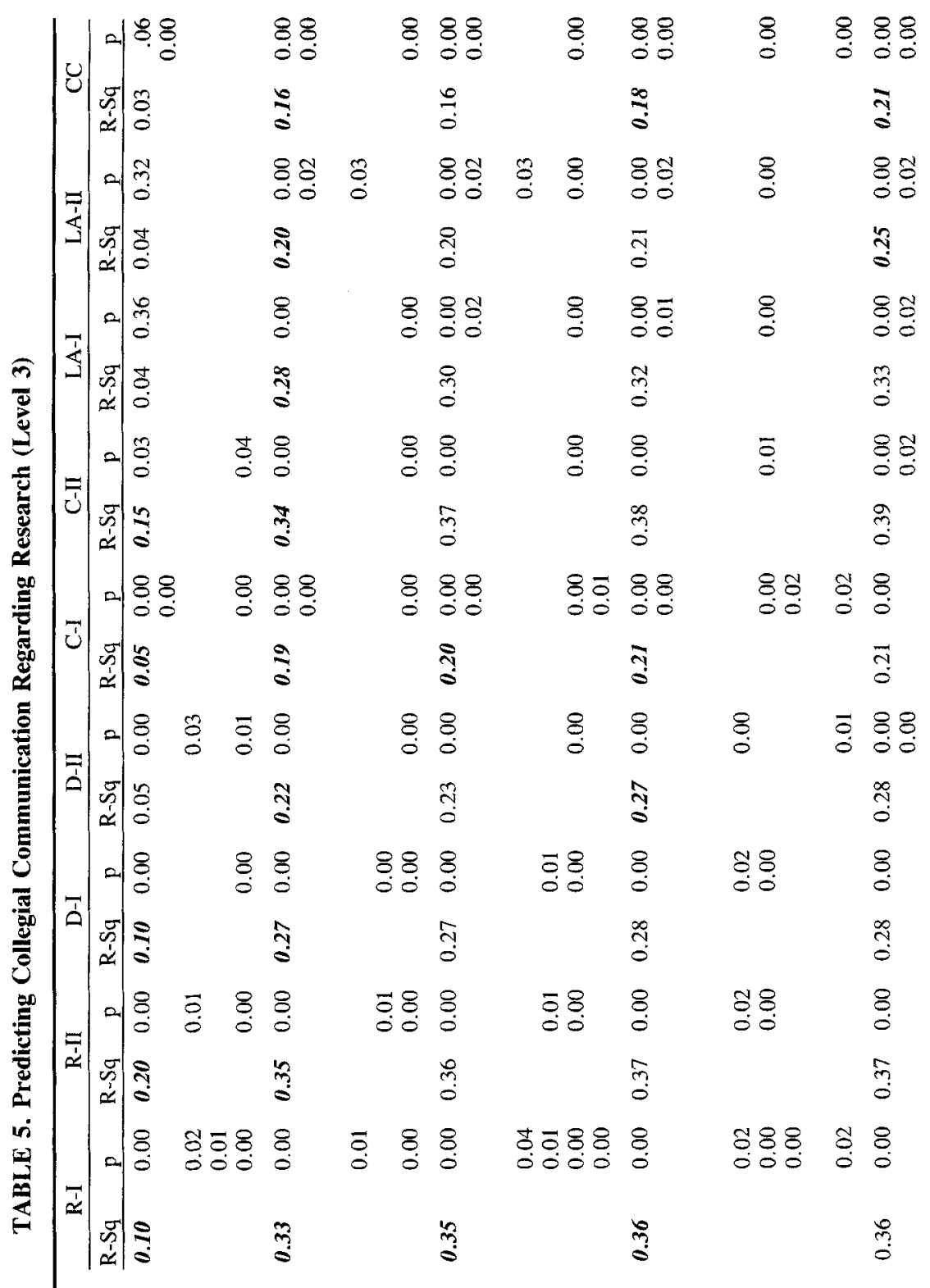

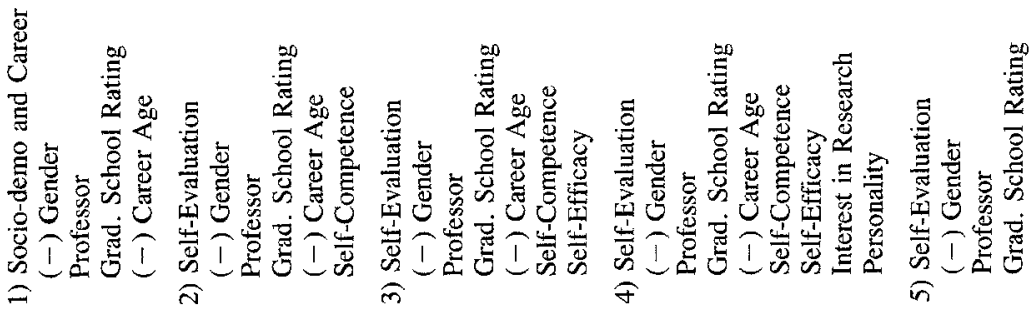




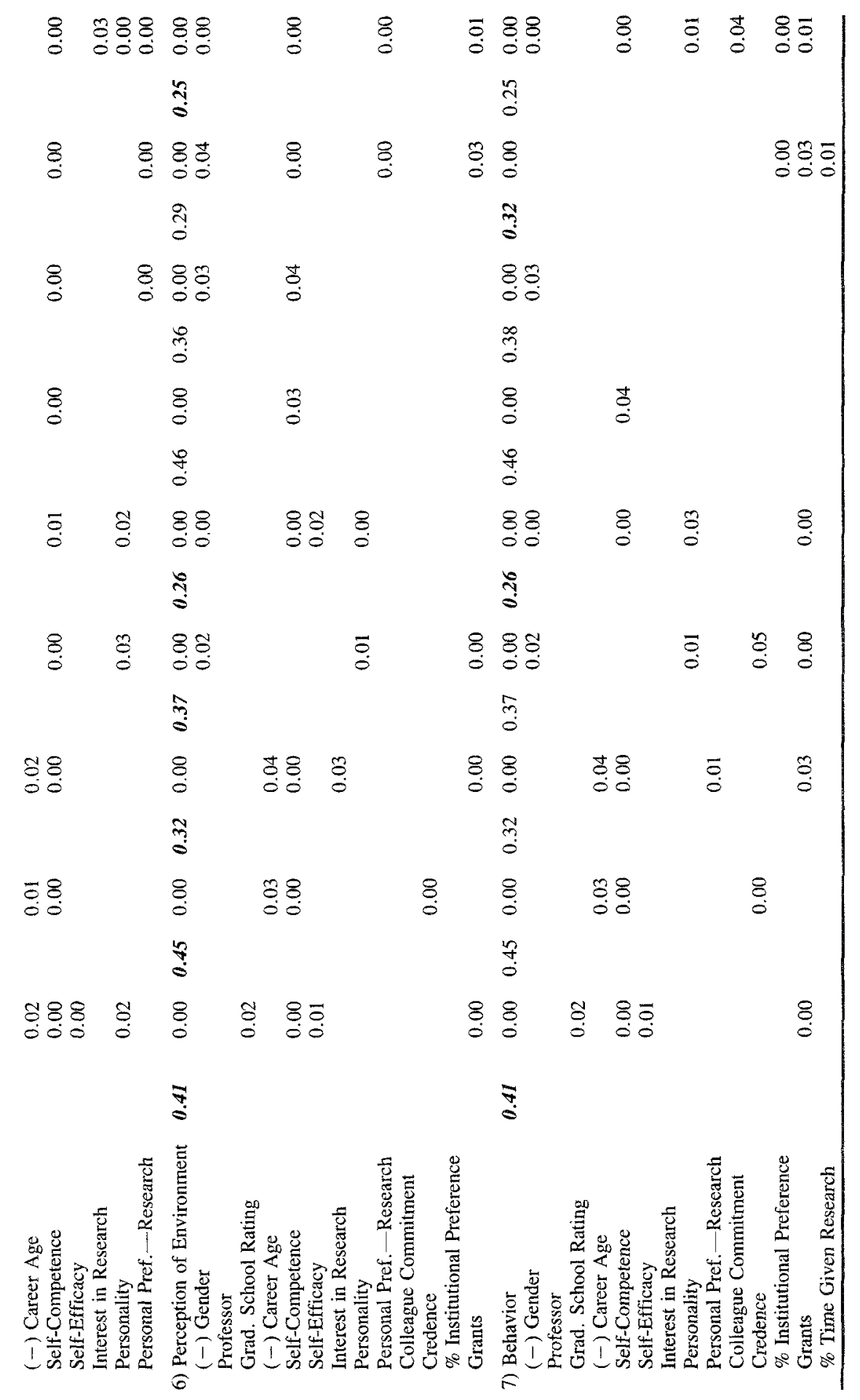




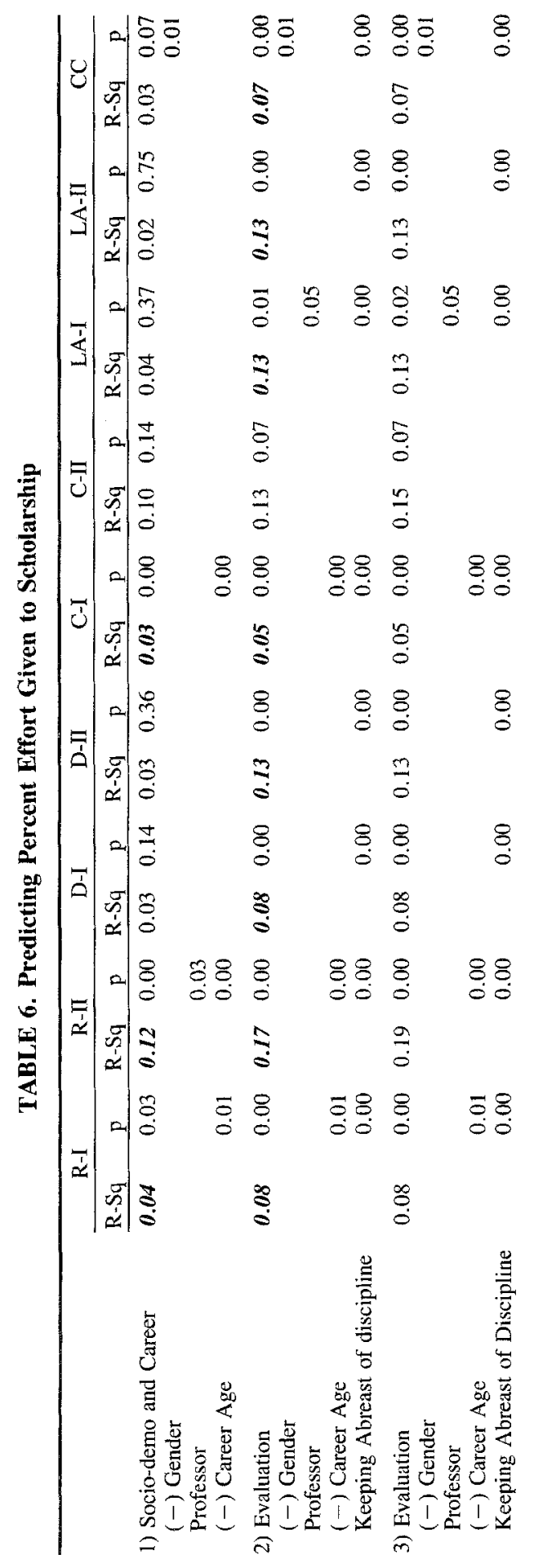




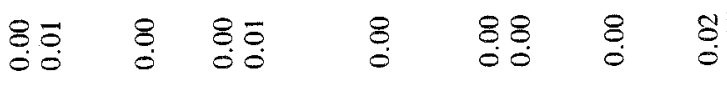
: $\quad \begin{array}{ll}0 & 8\end{array}$

$\begin{array}{llllll}\overline{0} & 8 & \overline{0} & 8 & \overline{0} & 8 \\ 0 & 0 & 0 & 0\end{array}$

$\stackrel{m}{0} \stackrel{\frac{1}{0}}{0}$

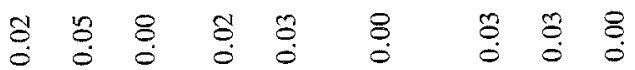

$\stackrel{m}{0} \quad \frac{n}{0}$

\begin{tabular}{llllll}
\hline & 0 & 0 & 0 & 0 \\
0 & 0 & 0 & 0 & 0 \\
0 & 0 & 0 & 0
\end{tabular}

$\stackrel{0}{\circ}$ กู

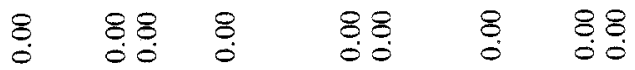

$\stackrel{8}{8} \quad \stackrel{8}{0} \quad \stackrel{8}{0}$

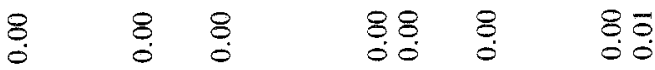

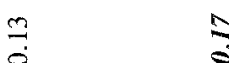

$\begin{array}{lllllll}8 & 8 & 5 & 8 & 8 & 8 & 8 \\ 0 & 0 & 0 & 0 & 8 & 0 & 0\end{array}$

$\stackrel{0}{0} \quad \stackrel{0}{0} \quad \frac{9}{0}$

$\begin{array}{llllll}8 & 58 & 8 & 85 & 8 & 8\end{array}$

)

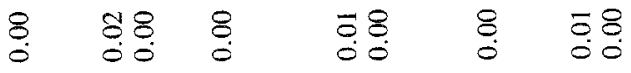

$\stackrel{8}{0}$

$\stackrel{8}{8}$

$\stackrel{8}{8}$

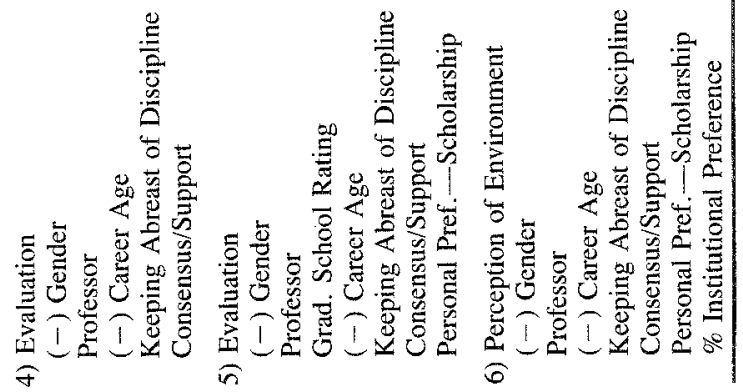


types of grants) in six. A new finding for this outcome variable is the credence that faculty give to colleague and administrator comments about their research, significant in D-I, LA-I, and CCs. The feedback of a respected administrator can make a difference.

In some ways, the third outcome measure of research activity, collegial conversations-frequency of talking about your research with colleagues at professional conferences or by phone (Level 3)-produced unexpected results. Besides providing a high percent of variance accounted for $\left(R^{2}=.36\right.$ on the average, higher than professional presentations), a wider assortment of predictor variables emerged.

Self-competency and financial support (grants) still dominated (in six of the institutional types). However, for the first time women (gender) and people with ambitious, competitive personalities (commitment to research/personality) become significant predictors (in four and three institutional types, respectively). It may be the case that some people who are not part of the "old boy" network and are striving to improve their lot in the academic pecking order of institutions may be using communication links to increase their publication output.

Turning to scholarship as the outcome variable, recall that it was defined for the respondents as being similar to "professional growth-time spent enhancing your knowledge or skill in ways which may not necessarily result in a concrete product-library work, reading, exploratory inquiries, computer use." ${ }^{10} \mathrm{Al}-$ though the $R^{2} \mathrm{~s}$ are appreciably lower than they were for research, they are all statistically significant (see Table 6). Self-competence-being good at keeping abreast of the discipline-was the significant predictor in eight of the nine institutional types.

Career age in research universities and in C-Is was also a significant predictor. However, while younger faculty at these types of institutions predicted percent of effort given to scholarship, so did being a full professor at LA-I institutions. These senior faculty may be akin to the "Mr. Chips" stereotype that is associated with this institutional type.

Service was divided into three types: public (dealing with the nonacademic outside world), professional (working with associations, for example), and campus (committees, etc.). Public service was eventually dropped from the analyses since we had but a single, unacceptable behavioral item existing in that category.

With respect to professional service, as can be seen in Table 7, the $R^{2}$ s were significant in six of the nine institutional types, but only once was more than 20 percent of the variance accounted for (in R-IIs). That full professor was a significant predictor for professional service in R-Is through D-IIs is not surprising since this kind of contributed time typically falls to those who have established a national reputation on the disciplinary scene. Further, this activity is related 


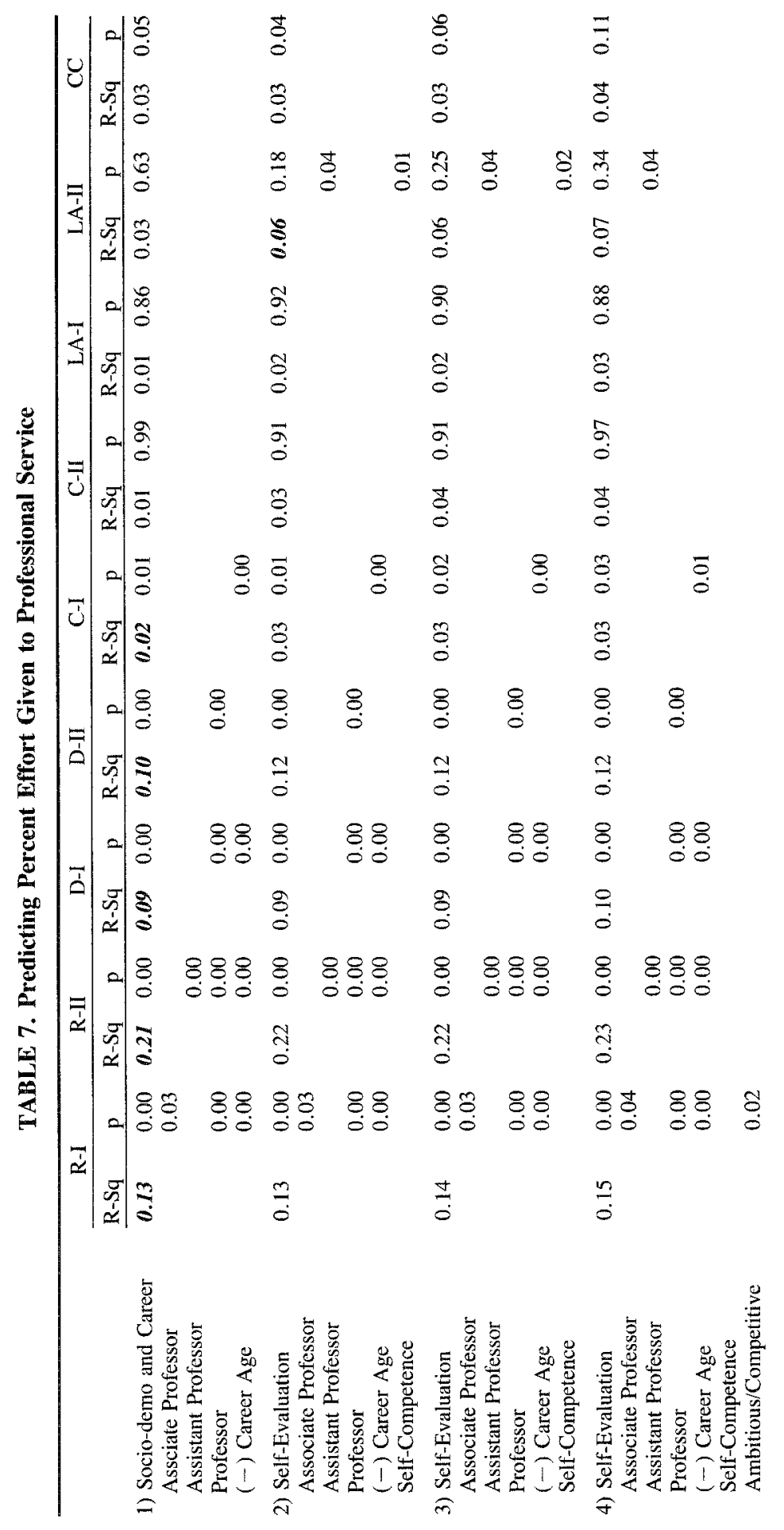




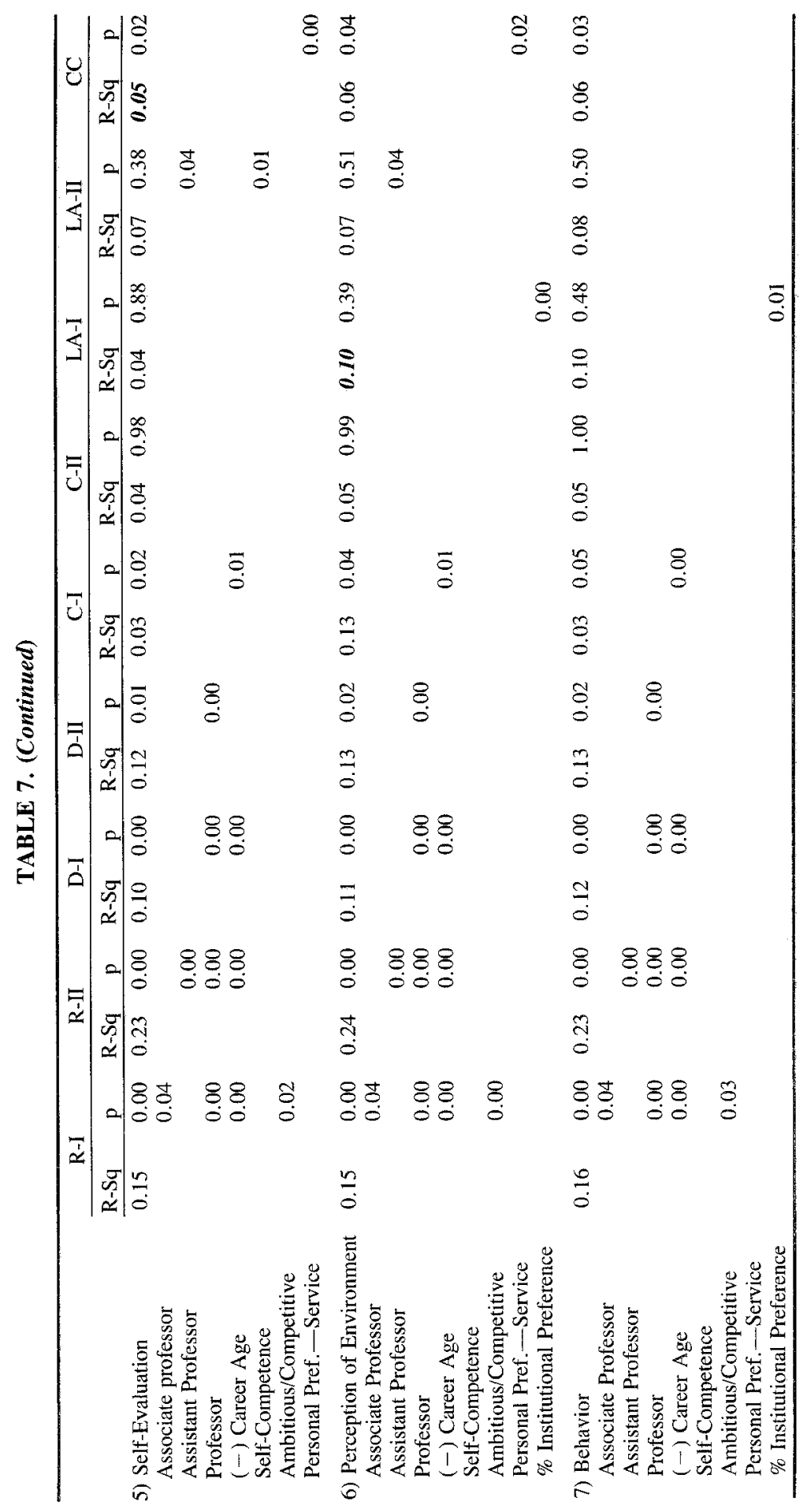




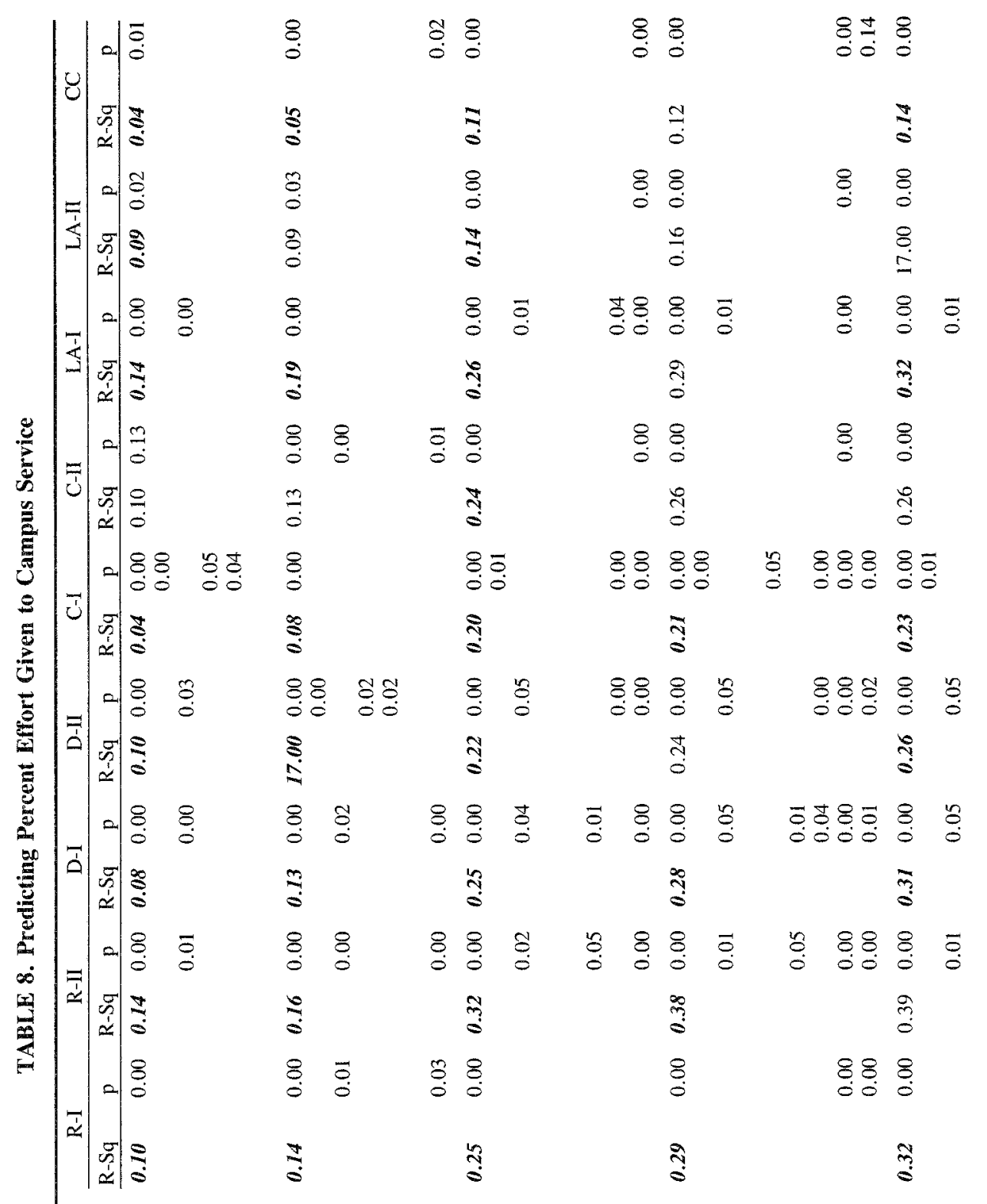

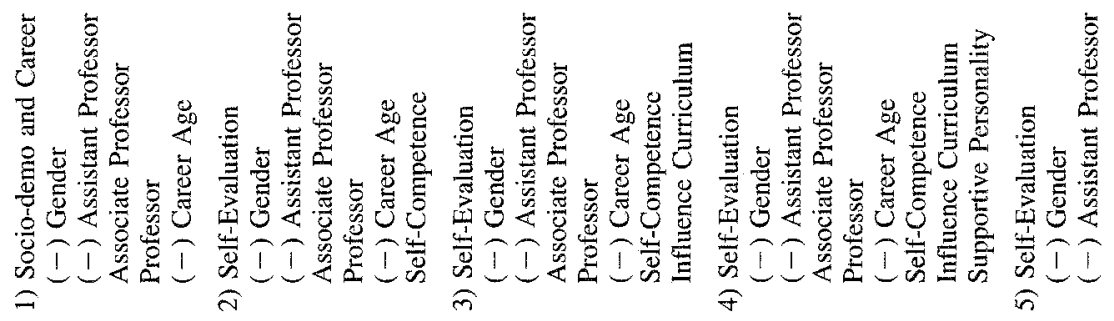




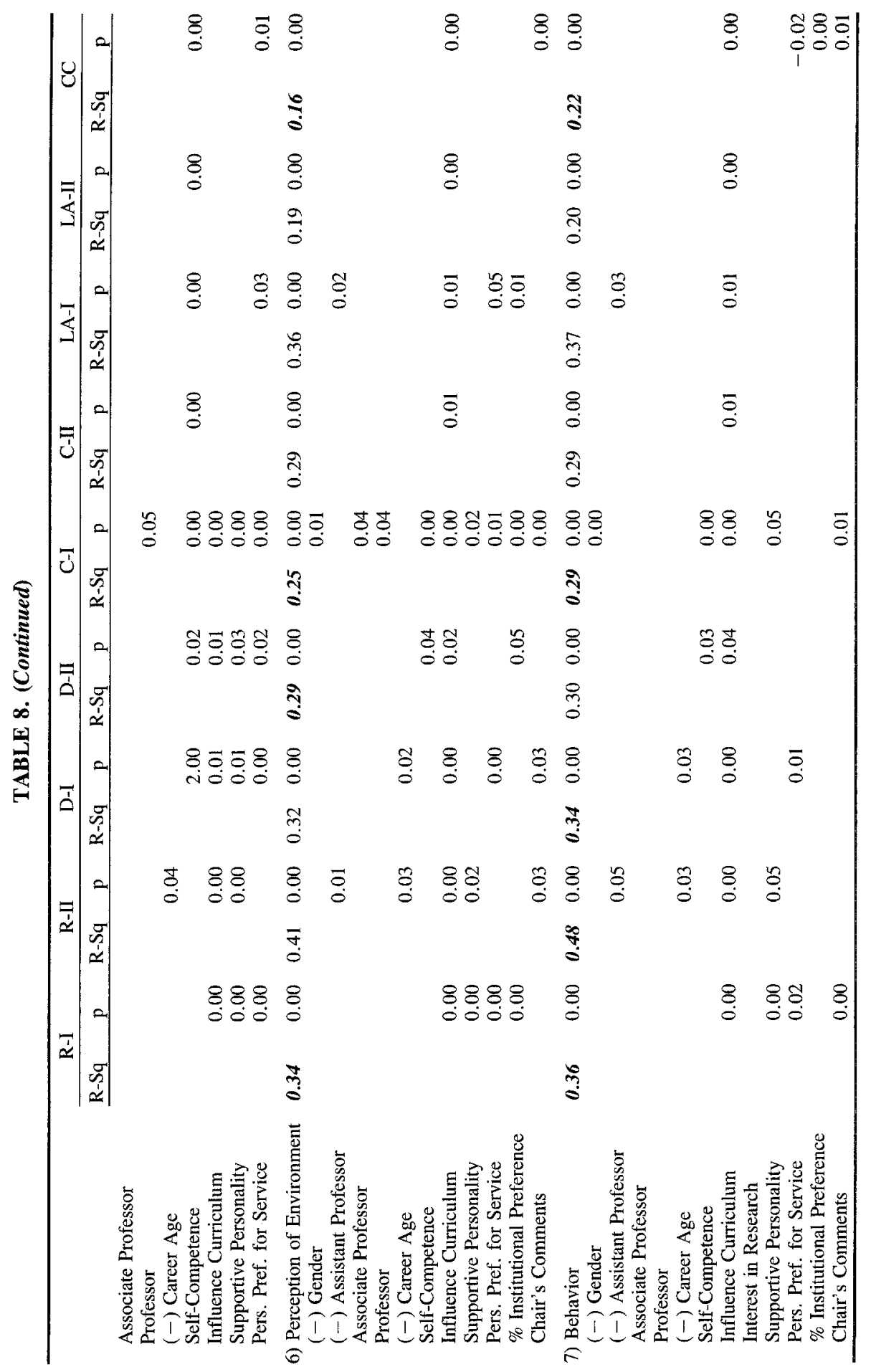


to research and less likely to occur as often in the other institutional types. What is not clear from these results is why those with less than average career age are also predictors (for R-I, R-II, and D-I institutions). It may be that since these types of institutions have more full professors than any other rank, it is the newly promoted full professors who are called upon to carry on this kind of professional work.

The $R^{2} \mathrm{~s}$ for service on campus are all significant and larger than anticipated for such an unvalued activity. Serving on a campus committee, being involved in curriculum revision, chairing a committee of your unit, and solving a unit problem are seldom voiced as desired activities. However, as Table 8 shows, as much as 48 percent of the variance was accounted for in R-IIs.

The self-efficacy indicator, namely, believing one has influence on curricular decisions within the faculty member's unit, was significant in all institutional types. A number of other variables entered in more than one institutional type: being older (career age), being a team player and devoted to the institution (commitment/supportive personality), institutional preference for this kind of service, and chair's comments on a professor's service work (credence). What this says to department chairs is that faculty who believe they can affect the outcomes of their labor for work-related matters will give time and effort. At the same time, those who believe they have little influence on outcomes will not devote time and effort to service activities.

Overall, then, despite some limitations, ${ }^{11}$ the widespread strength of the $R^{2} \mathrm{~s}$, despite the limited scales for some dependent variables, lends strong support for the theoretical model that anchors the research. On one or more occasions self-valuations and perceptions of the environment were significant predictors of behaviors and products, much more frequently than were sociodemographic and career variables, the ones typically employed in research on faculty.

The implications for practice seem clear. If it is important for an institution to increase outcomes on research, scholarship, and service, then activities that will make it possible for faculty to increase their competencies should be supported. There should be opportunities for faculty to participate in activities where they can see that what they do genuinely makes a difference. For example, professional development activities (such as research proposal writing workshops) should be made available to faculty. Administrative leadership can enhance faculty growth and performance, outcomes that will benefit the institution as well as the individuals.

Acknowledgments. This research was supported in part by a grant from the Office of Educational Research and Improvement/Department of Education (OERI/ED) under Grant G008690010, Project 117GH70004. However, the opinions expressed herein are those of the authors and do not necessarily reflect the position or policy of the OERI/ED and no official endorsement of the OERI/ED should be inferred. We are indebted to 
Steven Gaither, Bryan Leudy, and Christopher Mackie for their assistance with the data and their editorial contributions.

\section{NOTES}

1. In a recent study of job preference and selections of new economic Ph.D.s from leading graduate departments, Barbazet (1990) found women sought and selected academic positions over private sector ones. Furthermore, their choices were appreciably greater than men's for liberal arts colleges than for research universities, institutions where the teaching role dominates.

2. Two recent studies have investigated self-efficacy of university faculty (Landino and Owen, 1988; Schoen and Winocur, 1988). However, each has limitations of either sample size or response rate. Their work was not known until after this inquiry was completed.

3. This option arose in only five departments so the distortion from pure randomness is minute.

4. Essentially by definition, items in a factor are statistically related. They also can be seen to be functionally related, as is the case here. That this factor predicts (it does) scholarly output may not be surprising. However, this is a self-assessment of one's competence, not a behavior. Some of our high face validity factors turn out not to be significant predictors when other variables are controlled for.

5. The items are interrelated and correlated. However, they are not identical. Submitting an article to a professional journal is not having it published. Nor is submitting a proposal the same as getting a grant. They are not a factor but a simple scale from adding the seven items.

6. Regressions for this variable were understandably low and are not reported here. Also, using one's expertise to illuminate an issue on radio or television is not an adequate indicator of public service. Here one would think of activities like serving on a school board or city council as dimensions of public service. The item we used was the only one on the instrument in this domain.

7. Actually sixty-three were run but one of the service variables, public service, has been dropped. See below.

8. When $R^{2}$ is italicized and printed in boldface in the table, the increase in the $\mathrm{R}^{2}$ from the previous step is significant at $p<.05$.

9. For example, having gone to an R-I theoretically would motivate future faculty members to do more research than would faculty members who did not go to a R-I institution. See Discussion section regarding causality.

10. Note also that the dependent variable here is percent of work effort given to scholarship, a behavior, not a product.

11. For example, the survey was designed first of all to gather insights into faculty motivations related to teaching. Also academic disciplines were not entered since the $N$ 's would have been too small.

\section{REFERENCES}

Allison, P. D., and Stewart, J. A. (1974). Productivity differences among scientists: Evidence for accumulative advantage. American Sociological Review 39(4): 596-606. Astin, H. S. (1978). Factors affecting women's scholarly productivity. In Helen S. Astin and Werner Z. Hirsch (eds.), The Higher Education of Women, pp. 133-157. New York: Praeger.

Astin, H. S. (1984). Academic scholarship and its rewards. In M. W. Steinkamp and M. Maeher (eds.), Advances in Motivation and Achievement, vol. 1. JAI Press, pp. 259-279. 
Baldwin, R. G., and Blackburn, R. T. (1981). The academic career as a developmental process: Implications for higher education. Journal of Higher Education 52(6): 598614.

Bandura, A. (1977). Self-efficacy: Toward a unifying theory of behavioral science. Psychological Review 84(2):191-215.

Bentley, R. J., and Blackburn, R. T. (November 1990). Relationship of faculty publication performance with age, career age, and rank. Paper presented at the annual meeting of the Association for the Study of Higher Education, Portland, OR.

Blackburn, R. T., Boberg, A., O'Connell, C., and Pellino, G. R. (1980). Project for Faculty Development Program Evaluation. Ann Arbor: University of Michigan, Center for the Study of Higher Education.

Blackburn, R. T., and Lawrence, J. H. (1986). Aging and the quality of faculty performance. Review of Education Research 23(3): 265-290.

Blackburn, R. T., Lawrence, J. H., Bieber, J. P., and Trautvetter, L. C. (1991). Faculty at work: Focus on teaching. Research in Higher Education (in press).

Blackburn, R. T., and Mackie, C. (1990). Test-Retest Reliability Coefficients: Faculty at Work. Ann Arbor: University of Michigan, NCRIPTAL.

Boyer, C. M., and Lewis, D. R. (1985). And on the Seventh Day: Faculty Consulting and Supplemental Income. AAHE-ERIC Higher Education Report No. 4. Washington, DC: Association for the Study of Higher Education.

Breneman, D. W., and Youn, I. K. (1988). Academic Labor Markets and Careers. New York: Palmer Press.

Carnegie Foundation for the Advancement of Teaching (July 8, 1987). A classification of institutions of higher education. Chronicle of Higher Education 33(43): 22-30.

Carnegie Foundation for the Advancement of Teaching (1989). 1989 National Survey of Faculty Data. Princeton, NJ: Camegie Foundation.

Clark, M. J., and Centra, J. A. (1985). Influences on the career accomplishments of Ph.D.'s. Research in Higher Education 23(3): 256-259.

Finkelstein, M. J. (1984). The American Academic Profession: A Synthesis of the Social Scientific Inquiry Since World War II. Columbus: Ohio State University Press.

Gilligan, C. (1982). In a Different Voice. Cambridge, MA: Harvard University Press.

Ladd, E. C., and Lipset, S. M. (1975). Technical Report-1975 Survey of the American Professoriate. Storrs: University of Connecticut, The Social Science Data Center.

Landino, R. A., and Owen, S. V. (1988). Self-efficacy in university faculty. Journal of Vocational Behavior 33: 1-14.

Lawrence, J. H., and Blackburn, R. T. (1985). Faculty careers: Maturation, demographic, and historical effects. Research in Higher Education 22(2): 135-154.

Schoen, L. G., and Winocur, S. (1988). An investigation of the self-efficacy of male and female academics. Journal of Vocational Behavior 32: 307-320.

Staw, B. B. (1984). Motivation research versus the art of faculty management. In J. L. Bess (ed.), pp. 63-83. College and University Organization: Insights from the Behavioral Sciences. New York: NYU Press.

Tuckman, H. P., and Leahey, J. (1975). What is an article worth? Journal of Political Economy 83(5): 951-967.

Received July 5, 1990 